Utah State University

DigitalCommons@USU

$5-1957$

\title{
The Use of Branchiostegal Rays to Determine Age of Lake Trout Salvelinus namaycush Walbaum
}

Ross Vivian Bulkley

Utah State University

Follow this and additional works at: https://digitalcommons.usu.edu/etd

Part of the Aquaculture and Fisheries Commons, and the Environmental Sciences Commons

\section{Recommended Citation}

Bulkley, Ross Vivian, "The Use of Branchiostegal Rays to Determine Age of Lake Trout Salvelinus namaycush Walbaum" (1957). All Graduate Theses and Dissertations. 6321.

https://digitalcommons.usu.edu/etd/6321

This Thesis is brought to you for free and open access by the Graduate Studies at DigitalCommons@USU. It has been accepted for inclusion in All Graduate Theses and Dissertations by an authorized administrator of DigitalCommons@USU. For more information, please contact digitalcommons@usu.edu.

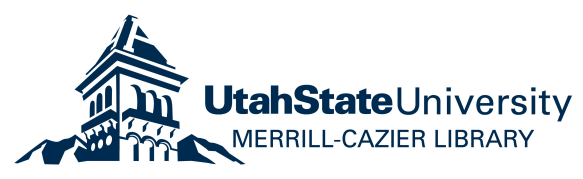




\section{PROPENTY OF UTAY WTOLFE: \\ LIBRARK}

THE USE OF BRANCHIOSTEGAL RAYS TO DETERMINE AGE OF LAKE TROUT

SALVELINUS NAMAYCOSH WALBAUM

by

\section{Roes Vivien Bulkloy}
A thesis submitted in partial fulfillment
of the requirements for the degreo
of
MASTER OF SCIENCE
in

Fisheries Management
Otah State Agricultural College
Logan, Otah

1957 


\section{ACKNOWLEDGMENT}

I here express thanks to Dr. William F. Sigler, head of the Departof Wildlife Management, Utah Stato Agricultural College, for suggesting this study and for his counsel and advice during the collection and analysis of the data. Thanks are due also to John Neuhold, William Clark, and William MoConnell of the graduate school for their assistance and suggestions, and to my wife, Evie, for her support and patience. 
Page

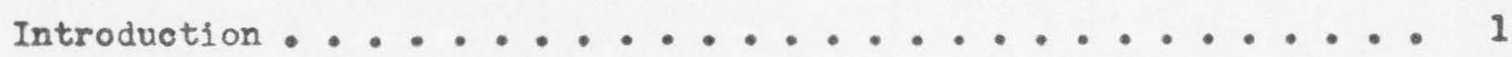

Description of study srea ................. 3

Collection and analysis of data ............... 4

Definition of annuli ................. 7

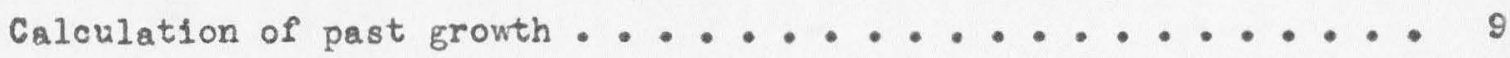

Evaluation of method ..................... 12

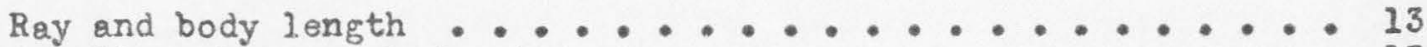

Annuli number and body size ................. 13

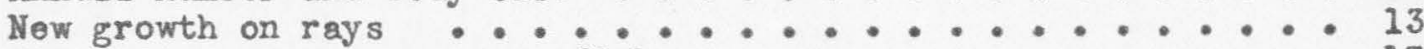

Similarity of rays on same fish .................... 17

Measured and calculated body length ...................... 17

Branchiostegal rays versus sealos ............... 19

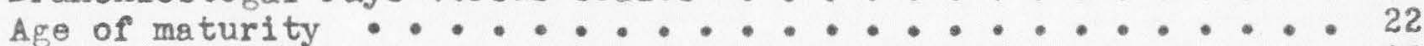

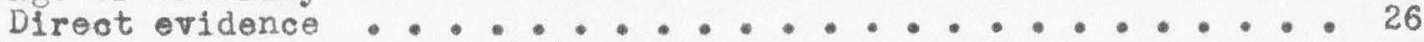

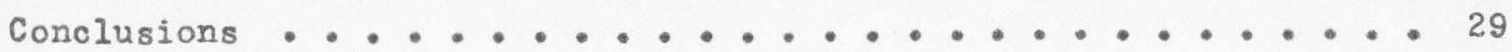

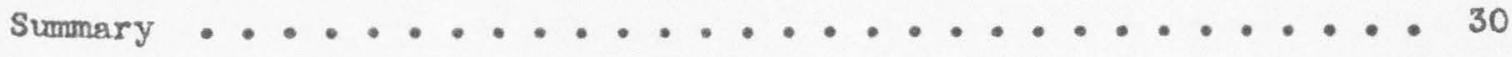

Literature cited .................... 31 
Table

1. Mean calculated standard lengths and increments of length for Fish Lake lake trout oollected during the sumer of 1956, with no differentiation by sex . . . . 10

2. Increase in width of new growth on branchiostegal rays of Fish Lake lake trout with the progress of the season - 16

3. Comparison of measured lengths of 305 Fish Lake lake trout with orlculated lengths determined by use of branchiostegal rays.

4. Agreement in age assessment of 305 Fish Lake trout by soale and branchístegal ray reading . . . . . . 24

5. Amount of disagreement in age between branchiostegal ray method and seale method of 8 Pish Lake lake trout 11 yoars of age and older... . . . . . . . .

\section{LIST OF FIGURES}

Figure

1. Method used to measure distanoe from focus ( $f$ ) of ray to each annulus . . . . . . . . . . 6

2. Body-branchiostegal ray relationship of Pish Lake lake trout as determined from 305 fish, colleoted in 1956 . . . II

3. Range in length and weight of Fish Lake lake trout for each age class as determined from $305 \mathrm{fish}$. . . . 14

4. Outer branchiostegal rays from the left and right side of a Fish Lake lake trout aged at 3 years . . . . . . 18

5. Branchiostegal rays and scale from a Fish Lake lake trout whose age was estimated at 6 years . . . . . . . 23

6. Branchiostegal ray from Lake Michigan lake trout whose known age is 4 years 


\section{INTRODUCTION}

Any method used in aging fish must fulfill certain requirements to be satisfactory. If the method is inaccurate, naturally little reliance can be plaoed upon its use. If considerable study of the method and much practice are required before accurate readings can be obtained, the method will not come into widespread use. The requirements of an aging method, then are that, it must be accurate and comparatively easy. The 8 cale method for aging lake trout (Salvelinus namaycush Walbaum) unfortunately does not fulfill these requirements. It has always been difficult to tell the age of lake trout by the examination of scales--the standard method of aging most fish. Although a few researchers have successfully aged lake trout by the scale method, much training is necessary to be proficient. Older fish are particularly difficult to age by the scales.

This lack of an easy and dependable aging method is hampering growth studies of lake trout in Dtah lakes. Hence, in 1956, the Department of Wildife Management at the Utah State Agricultural College and the Utah Department of Fish and Game began a study at Fish Lake, Utah, to determine the value of branchiostegal rays as growth indicators of lake trout. The branchiostegal rays are small semi-transparent bones located in the branchiostegal membrane, a ventral extension of the operoulum. The number of these rays varies according to species of fish.

Various bony structures have been used in place of scales for deter mining age and growth rates. LeCren (1947) and MoConnell (1951) used the opercular bone to age perch and carp. Appelget and Smith (1951), Lowis (1949), and Zarbock (1951) used the vertebrae. Boyko (1946) and Cuerrier (1951) used fin rays to determine age of fish. Otoliths have also been used oocasionally. Menon (1949) presented a complete list of the different bones that have been used for age determination in fishes, together with the names of the workers who have used them.

of the bones considered for use in aging lake trout, the branchiostegal 
rays were considered most promising. Different bones in the head were checked for markings which might be growth indioators. Markings on the branchiostegals were found to have all of the characteristics of annull and were used, therefore, in this study.

Branchiostegal rays were also chosen because of the ease of obtaining specimens. Most lake trout samples must come from the fisherman's creel, and fishermen do not want their fish defaced by the removal of large or deeply-centered bones in the head or body. This is especielly true for flsh which the fisherman wishes to mount or photograph. Hence neither the operoular bone nor the vertebrae would be suitable. The small size and surface location of the branchiostegal rays eliminate this difficulty in obtaining specimens. One ray on either side of the head can be removed and only a small deformation results. Also many fishermen remove the isthmus and branchiostegal membrane when cleaning the fish. Thus the rays can be obtained easily.

Another possible advantage in using the branchiostegal rays is that the oareful removal of a single ray apparently does not oause serious injury to the living fish. This would make it possible to check the age of a fish without killing 1t--one of the advantages of using scales. Iim1ted observation of small fish of several species indicates that fish have a good chance of survival after removal of a single branchlostegal ray. However, this possibility was not explored in the present study. More investigation is necessary to determine the long-range effects of branchiostegal ray removal from lake trout before it is attempted on large numbers of fish. 


\section{DESCRIPTION OF STUDY AREA}

The fish of unknown age used in this study were taken from creels of fishermen at Fish Lake, Utah. Fish Lake is perhaps the best habitat for lake trout in Utah. It is located in Fish Lake National Forest, Sevier County, and lies at an eleration of 8,800 feet. The lake was formed by a graben and is oligotrophic in nature. It is $5 \frac{1}{4}$ miles in length and has an average width of three-fourths of a mile. The surface is roughly 2,500 acres. The long axis of the lake extends in a northeast-southwest direction. The shore on the southeast side is precipitous and rocky, and a few yards offshore a shelf drops off to a depth of 90 feet or more. This area of the lake provides a suitable spawning grounds for the lake trout.

Water temperatures were taken regularly during the sumer of 1956 with a bathythermograph. Surface temperatures varied from $51^{\circ}$ to $63^{\circ} \mathrm{F}$. during this period (June 16 to september 17). A distinot thermooline extended to a depth of 60 feet where the temperature was $45^{\circ} \mathrm{F}$. The hypolimnion remained at a fairly constant temperature of $43^{\circ}$ to $44^{\circ} \mathrm{F}$. These temperatures differ slightly from those recorded by Hazzard (1935). However, they still $\mathrm{fall}$ between $40^{\circ}$ and $45^{\circ} \mathrm{F}$., the temperature necessary for a suitable lake trout nabitat.

The lake trout was first introduced into Fish Lake along with the brook trout Salvelinus fontinalis (M1tohell) in 1906. It was not immediately successful, but since that time the lake trout has adapted to the lake, and the population is now quite numerous. It is now one of the lake "s main attractions to fishermen because of its large size. 


\section{COLLECTION ANI ANALYSIS OF DATA}

The fork, stendard, and total length of 305 lake trout captured in 1956 at Fish Lake were recorded. Measurements were taken to the nearest one-eighth of an inch with a steol tape. Weights were recorded to the nearest ounce. These measurements were considered sufficiently accurate because of the large size of the fish exemined and also because of the difficulty in carrying more courate equipment in the field.

Samples of scales from the standard location between the anterior ond of the dorsal fin and the lateral line were taken from each fish. Fish were classified as mature if the eggs were grossly visible in the ovaries or if the testes showed development. Some of the fish listed as mature would not have spawned, therefore, for enother year. Fish with undeveloped gonads were listed as immature, and no attempt was made to sex them.

The outer branchiostegal rays adjacent to the loft and right opercular bones were taken for this study. Both rays were taken because occasionally one ray was deformed or broken. Using a partioular ray employs all the adventages obtained by using key scales. There is no variation In size or development due to taking the structures from different reas of the body. To remove the rays, a sherp knife was inserted along each side of the ray to sever the connecting skin. It was necessary to remore the ray carefully so that the base of the ray containing the focus was not cut off. Best results were obtained by promptly removing the skin covering the ray before it dried out. The flesh and skin were readily peeled of from rays of the smaller fish with the fingernail. A better method was to insert the ray in boiling water for $30-60$ seconds. The flesh was then pulled away very easily. It was difficult to remove the plesh from large branchiostegal rays in any other way. No other preparation of the rays was nocessary before reading. 
In the aotual reading, each ray was read independently three times to determine the age of the fish. The annuli on most rays were easily discernible without optical equipment. Doubtful rays were observed with a large reading glass or a hand lens. When the correct age was decided upon, the annull were marked with a dot of india ink to aid in relocating them for measurement.

Annuli near the edge of the ray on older fish were bunched closely together. This made it difficult to measure directly the distance between the focus and annuli without enlarging the ray. The rays were markod, therefore, with india ink in the general location of each annulus and then enlarged 3.4 times by projecting with a lantern-slide projector. This particular enlargement was chosen so that there would be minimum loss of distinctness of the markings, and also so the lengths obtained would fit directly on an ordinary nomograph. The rays were placed in a transparent plastic envelope for inserting into the projector. This method worked satisfactorily for rays of all sizes.

Oak tag strips were used for recording the projected ray length and distance from the focus to each annulus. A plastic ruler would also be satisfactory if lengths to osch annulus in millimeters were desired. The oak tag was bent so that it lay parallel to the curved inner edge of the ray enlargement for measurements as illustrated in figure 1. (Notice that the focus is at the very base of the ray.) The curved measurement wa assumed to be closer to the correct growth lengths than a stralght-line messurement. Allowance for curvature in the other plane was unnecessary because the rays were almost flat. The measurement of growth to each annulus was made from the focus to the posterior-most part of the annulue This maximum distance of each annulus from the focus was used so that all messurements would be uniform. 


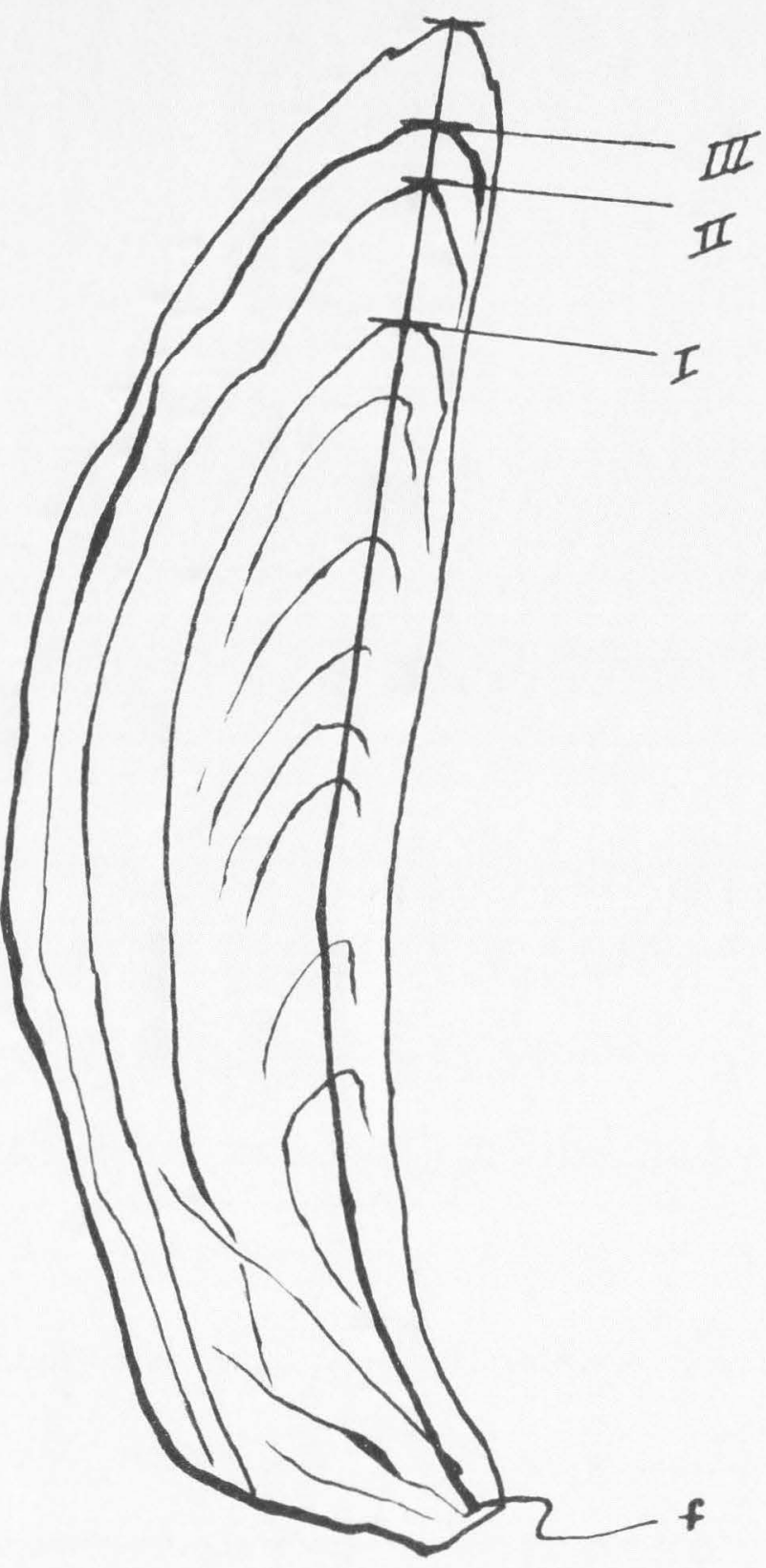

Figure 1. Method used to messure distance from focus ( $f$ ) of ray to each annulus 


\section{DEFINITION OF ANYLI}

Linear growth in the branchiostegal rays of fish is in one direction only---posteriorly. It is postulated that the ray is lengthened by the deposition of cells on the posterior edge. As this edge grows outward, a oomplete history of growth is recorded there just as on the scales. Thus the branchiostegal rays of lake trout aro marked by a series of white opaque bands divided by sharp transparent lines that run parallel to the outer edge of the ray. These lines were the outer edge of the ray at one time. The number of markings on the ray increases directly with an increase in the length of the rish.

The annuli are defined as narrow transparent lines located in the posterior and of the ray and extending also along the full length of the lateral fleld. These narrow lines of winter growth contrast sharply with the broad white bands of summer growth on most rays. Occasionally on oldor fish, the white area obscures these transparent lines, but another characteristic also helps to loote the annuli. A slight ripple of varying distinctness in the structure of the ray is present at each annulus. The direction of growth of the ray appears to change immediately after the annulus is laid down. This wave or ripple is important in locating the true anulus. If the ray is held so that light reflects from it to the eye, these wares stand out distinctly enough to mark all annuli on most rays. False annuli were often present in the rays examined, but were incomplete and did not extend far into the lateral field of the rayo The false ennuli also did not have the characteristio ripplo in the ray structure. The annuli of fish aged as 3 years or younger were not as distinct as the annuli on the rays of fish older than 3 yoars. It was easier, therefore, to age the mature fish. Markings on the rays of old Pish were espeoially distinct. This is in direct contrast to the process of aging lake trout by scales which become worn and indistinct with age. 
MoConnell (1951) in working with the opercular bone of carp had some diffioulty in locating the first annulus because of thiokening of the bone around the fulcrum. Only oceasionally did this occur with the branohiostegal rays of lake trout because branchiostegal rays are much thinner than the opercular bone. Most rays oven in older fish retained the first characteristic ripple of the annulus, and usually the trensparent line also, as the ray increased in size. Very little obsouring due to thiokening of the ray occured.

The annuli were seen most easily against a dark background in reflected light. A bright cloudy day provided the best conditions for reading the rays. Light from a tungsten lamp was inforior to diffused sunlight and fluoresoent lighting. The use of $X-r$ ay was considered as a check of the method, but it was not tried because of the costs involved. In an effort to make the markings more distinot, various stains were tested. Among these were basic fuohsin and alizarin red S. Alizarin red was used successfully by Galtsoff (1952) to stain the growth rings in the vertebrae of tuna. This made the annuli more distinct. It wes thought that branchiostegal rays would absorb the stain in a manner similar to the tuna vertebrae. However, none of the stains tested were of any ralue in making the annuli on the rays nore distinct. Unstained rays were the oa lest to read. 
CALCULATION OF PAST GROWTH

The relationship betwoen body length and branchiostogal-ray length of Fish Lake lake trout was determined from 305 specimens. This relationship is adequately expressed by the straight-line formulas

$$
L=7.19+4.45 \mathrm{R} \text {. }
$$

where $L$ is the standard length in millimeters and $R$ is the total ourved length $(x 3.4)$ of the ray in millimeters (figure 2).

Actual calculations of past growth (table 1) were made with the aid of a nomograph as described by Hile (1950). 
Table 1. Mean calculated standard lengths and increments of length for Fish Lake lake trout collected dur1nE summer, 1956

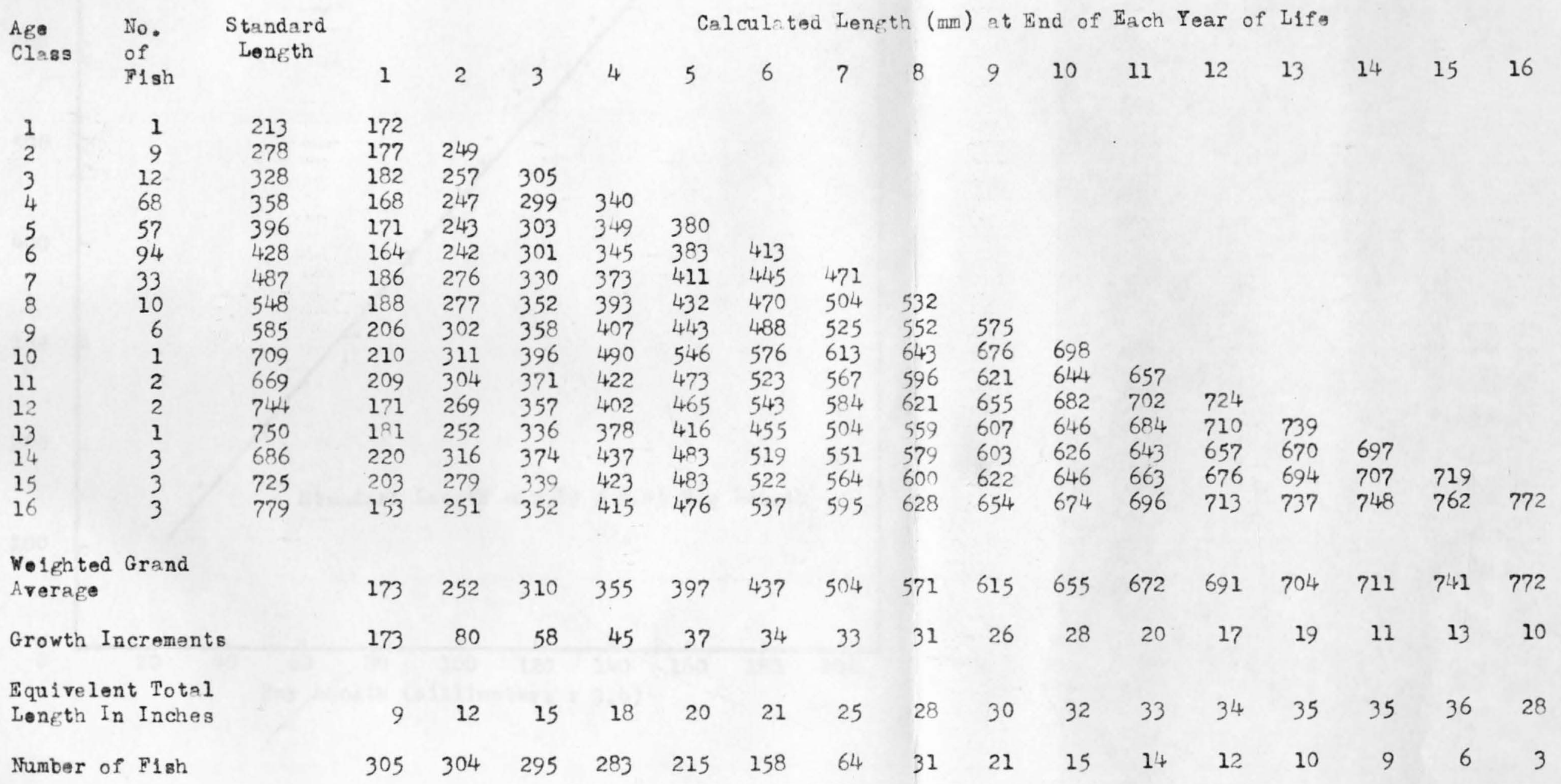




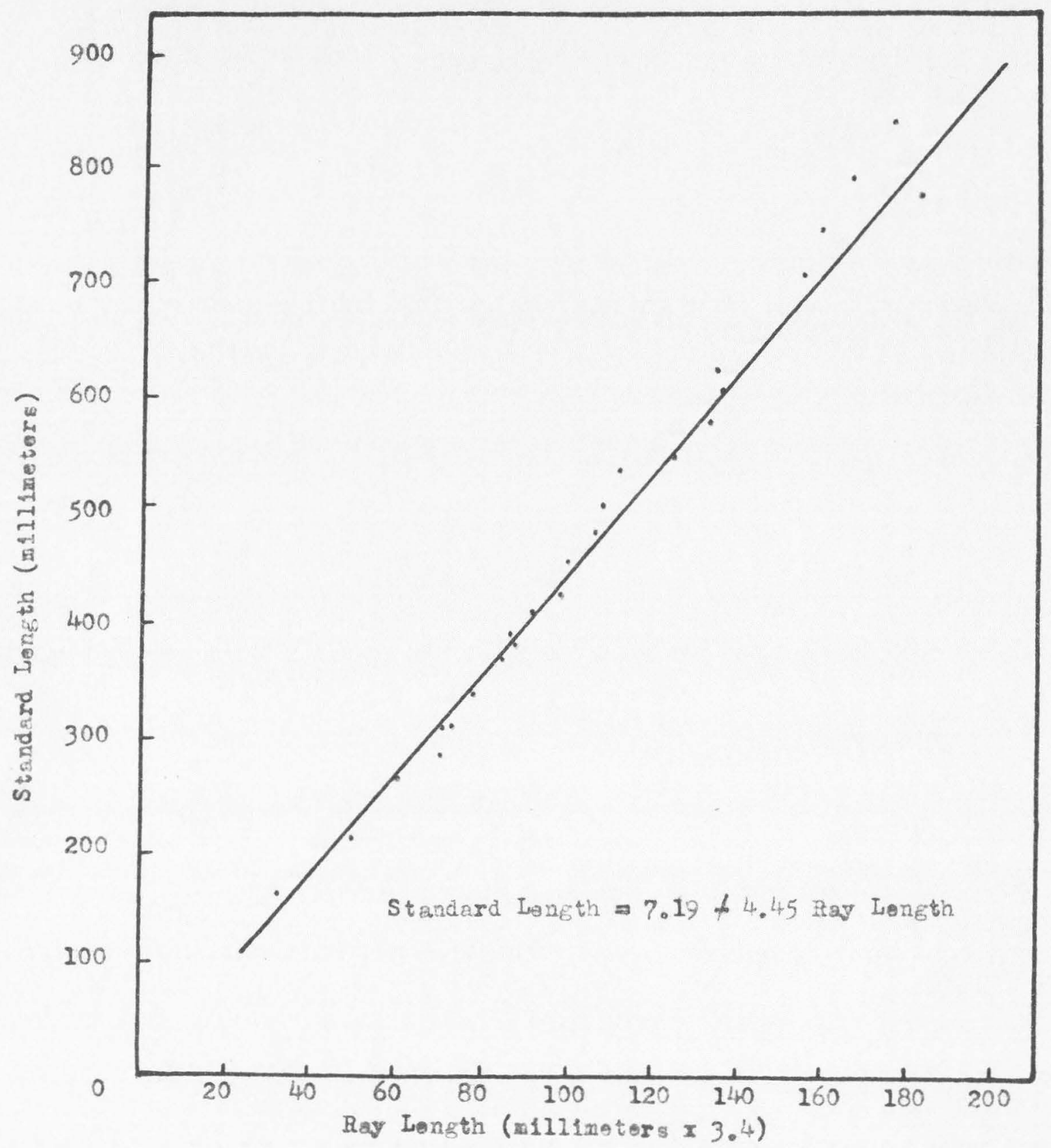

P1eur 2. Bedyobranchlostogal ray rolationghlp of Figh Lake lake trout as determined from 305 fleh, collected in 1956 


\section{EVALOATION OF THE METHOD}

Before on aging method oan be used confidently in life history studies of fish, evidence must be obtained to prove that the method is val1d. Direct evidence may be obtained that proves the method without doubt; or indirect evidence can be used which suggests that the method is valid.

Direct evidence may be obtained by the use of known-age fish or by comparing length frequencles in the same fish population for 2 or more consecutive years. As this study was conducted over a l-year period only, the latter method was not used. However, branchiostegal rays from 37 lake trout of known age were used in this study to substantiate the evidence obtained from fish of unknown age. The known-age fish were part of the collection used by Louella E. Cable in her study on the validity of aging lake trout by the soale method (Cable, 1956). The fish were marked and planted as fingerlings in Lake Michigan and recovered when 3, 4, or 5 years of age.

Indirect evidence was obtained from 305 lake trout of unknown age captured at Fish Lake, Utah. This indirect ovidence, which will be given first, was adapted from Van Oosten (1929) and is as follows:

1. There is correlation between the length of the aging structure (branchiostegal rays) and the length of the fish. The ray grows longer at a constant ratio as the body grows longer.

2. The number of annuli on the ray increases directly with fish size. The length and weight increases in gradual steps with the assigned age class。 3. The ray margin grows out from the last annulus as the growing season progresses.

4. Different rays from the same fish are similar in size and number of annuli present.

5. Calculated lengths obtained from the rays agree with empirical lengths 
of younger fish.

6. Age data acquired by the ray method agree with similar data from the scales.

7. Age assigned from branchiostegal ray reading agrees with the normal age when lake trout mature.

$R_{\text {Qy }}$ and body length

In order for the branchiostegal rays to be acourate indicators of age, they must be closely correlated with body size. There was high correlation $(r=0.961)$ between the length of branohiostegal rays and body length (figure 2). The body and the rays grew longer, therefore, at a constant ratio. The average ray length $(x 3.4)$ for fish in the 200-225 millimeter length group was 49 millimeters. This ray length inoreased for each length group up unt1l the 850-875 millimeter length group whioh had a ray length $(x 3.4)$ of 175 millimeters. Annuli number and body size

The number of annull present on the branchiostegel rays also increased directly with the size of the fish. A comparison was made between the number of annuli counted on the ray and the length and wight of the fish. Both the length and weight inoreased in gradual steps with increases in assigned ge (figure 3). This relationship 18 not as distinct in some age groups such as the XV-year group, where the number of fish in the group is very small. Ihis particular weight rango does not fall in the regular pattern of gradual increase, but the exception is assumed to be due to the small number of fish in this group. There is wide varlation in the weight of older $\mathrm{PIsh}$ in many species, 80 this is not unusual. The over-all pattern does show an inorease in s1ze with an increase in number of annuli on the branchiostogal rays.

New growth on rays

Another method of indirectly verifying an aging method is to follow the growth history of the marginal portion of a seale or bony structure throughout all or part of the year. As the body growth continues, the 


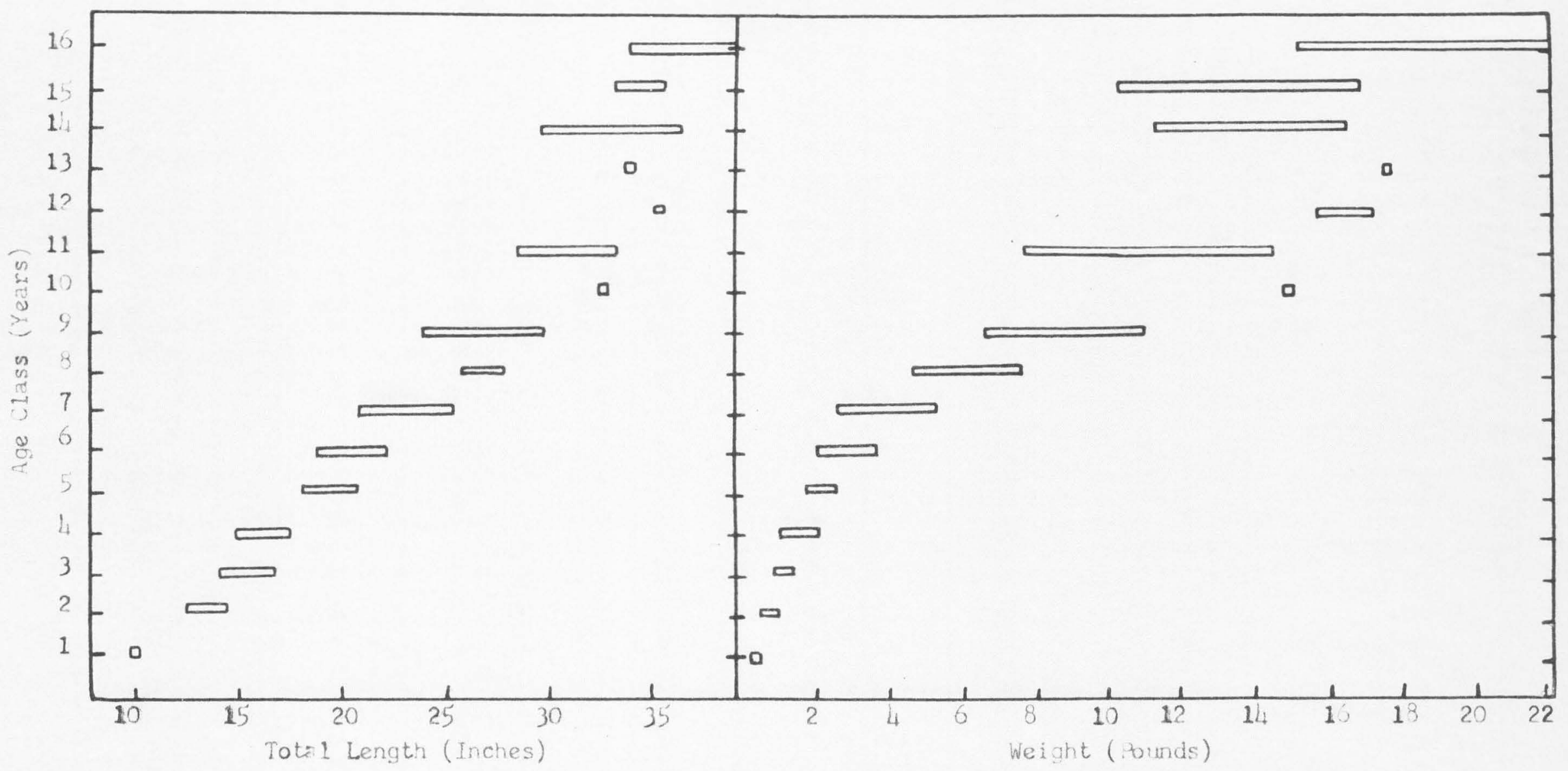

Figure 3. Range in length and weight of Fish Lake lake trout for each age class as determined from 305 fish 
outer edge of the soale grows progressively further from the last annulus. Finally, after a full year, another annulus is laid down and tho cycle repeats itself. Hence, the width of the soale beyond the outer annulus increases as the year progresses. If the aging structures of a fish, such as soales, were examined early in the growing season and then examined again later in the year, this band of summer growth would have increased in width. $\mathbf{A}_{\mathbf{B}}$ all acourate aging structures with annuluslike markings exhibit this characteristio, the branchiostegal rays were examined for indioations of this growth pattern.

Cable (1956) found that new growth was visible on scales of a few Lake Michigan lake trout as early as the latter part of March. The percentages of lake trout with new growth on their scales increased slowly through April and May, but rose rapidly through June and July. Fifty percent of the fish showed scale growth by the last week in June and the 100-percent mark was reached by the latter part of August.

Lake trout from Pish Lake, Utah, probably have growth conditions similar to those from Lake Michigan. New growth should be visible, therefors, on many of the branchiostegal rays of Fish Lake lake trout by June Examination of the rays revealed that new growth was present on rays of most of the fish captured during this month. The rays of the lake trout aged as 4-6 years in this study were examined to see if this new growth increased as the summer progressed. Only the 4,5 and 6 year age classes were used to reduce variation in rate of growth of very young or very old fish. The trout in these three age olssses were separated according to month of capture. The average width of the branchiostegal rays from the outer annulus to the ray edge for all fish captured in each month was then determined (table 2).

The average widths of new growth for July and August were found to be the same. This would seem to invalidate the aging mothod. Howerer, the use of different $\mathrm{flsh}$ instead of the same individual over the whole 
Table 2. Increase in width of new growth on branchiostegal rays of Fish Lake lake trout with the progress of the season

Month

Average distance from

annulus to ray edge (mm)

Number of fish captured

in erch month

$$
\text { June }
$$

0.101

84
July

0.116

0.116

August

September

0.126

59

55 
growing season introduces an error due to individual variations in growth.

Theoretically all fish of the same age should grow at the same rate。 As Cable (1956) indicated, though, some Lake Michigan lake trout showed eridence of growth on the scales as early as March, but others did not show growth unt1l August. This may account for the same average width of new growth for July and August in this study. Perhaps more of the fish oaptured in August had just commenced growing than those eaptured in July. If the growth of individual fish over the whole sumer could be observed, this error would not be present. Bren with the error due to using differ ent fish, the growth pattern over the 4 months does seem to indicate that the markings on the branchiostegal rays are true annuli. Average growth for June is less than for any of the succeeding months, and September has the largest average width of new growth on the rays. Similarity of rays on the same fish

4 The branchiostegal rays on lake trout are included in the branchiostegal membrane which is a ventral extension of the operculum. In this study the two branchiostegal rays adjacent to the opercular bones were used as they are the largest in the branchiostegal membrane. Apparently they are also the first to bo ossified in the young fish. These two rays from the opposite sides of the head were compared to determine if the number of annuli were the same on each. Observation showed that the rays were very similar (figure 4). The number of annuli was always the same on each pair examined. Ocoasionally an annulus on one ray would be more distinct than that on its mate, but after oomparison both annuli could be located. As both rays were so similar, the one showing the more distinct annuli was used in this study. Some error may have been introduced by not using the same ray at all times, but if so, it would probably be small.

Measured and calculated body length

Comparison was also made between oalculated body lengths determined 


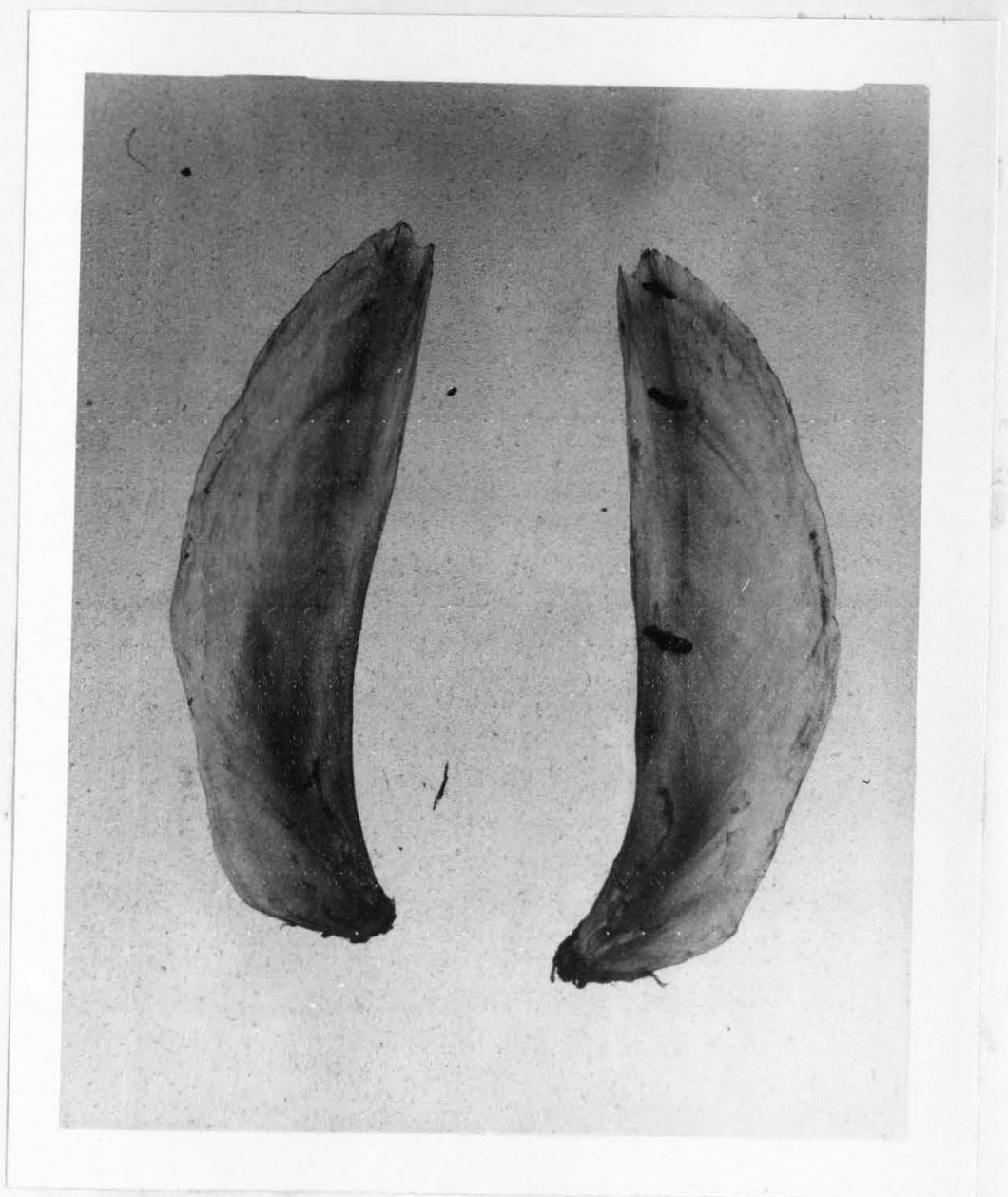

Figure 4. Outer branchiostegal rays from the left and right side of a Fish Lake lake trout aged at 3 years 
from the branchiostegal rays and measured length of younger fish. An aging method is based on the premise that some correlation exists between the body growth rate and growth rate of certain body struotures used in aging. Henoe, calculated lengths as determined by an aging method should agree well with empirioal lengths of younger fish. If there is wide disagreement between calculated length of younger fish and observed length of these fish, then the particular aging method is not valid. The growth of the structure used in aging would not be correlated with body growth. As indioated in the body-branchiostegal ray relationship. there is high correlation in growth between the two. The product moment correlation coefficient is 0.961 . This correlation is substantiated further by the comparison between oaloulated length determined from the rays and observed length of younger fish (table 3 ).

It should be noted that agreement is olosest where the number of fish is largest. A larger number of $\mathrm{fish}$ in a group would naturally tend to cancel out wide variations, and the average would be closer to the true mean. The average of a small number of fish might differ greatly from the true population mean. It is assumed that much of the error in the smaller groups was due to the small size of sample. The over-all comparIson was close enough to state that the calculated length as determined by the branchiostegal rays is a good estimate for practical purposes of the true average length of the fish.

Branchiostegal rays versus scales

The use of an aging method should also give results that are comparable to that obtained by other methods of determining age. There must be agreement if both methods are valid. Age determined by the branchiostegal rays should agree, then, with the age read from scales of the same fish. Seales of the lake trout obtained at Fish Lake were mountod and read for this comparison.

Scales were mounted in a sodium silicate-glyoerin base, and then 


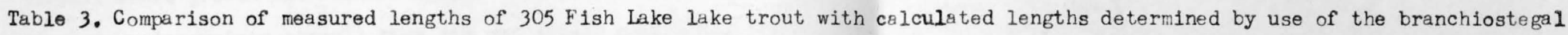
rays

\begin{tabular}{|c|c|c|c|c|c|c|c|c|c|c|c|c|c|c|c|}
\hline Age of fish (years) & 1 & 2 & 3 & 4 & 5 & 6 & 7 & 8 & 9 & 10 & 11 & 12 & 13 & 14 & 15 \\
\hline Number of $\mathrm{fish}$ & 1 & 9 & 12 & 68 & 57 & 94 & 33 & 10 & 6 & $\mathbf{1}$ & 2 & 2 & 2 & 3 & 3 \\
\hline $\begin{array}{l}\text { Measured standard } \\
\text { length }(\mathrm{mm})\end{array}$ & 213 & 278 & 327 & 358 & 396 & 428 & 487 & 548 & 585 & 709 & 669 & 744 & 750 & 686 & 725 \\
\hline $\begin{array}{l}\text { Calculated } \\
\text { standard length }\end{array}$ & 172 & 252 & 310 & 355 & 397 & $\$ 37$ & 503 & 571 & 615 & 655 & 872 & 791 & 704 & 711 & 741 \\
\hline $\begin{array}{l}\text { Numerical } \\
\text { difference }\end{array}$ & 40 & 26 & 17 & 3 & 1 & 9 & 17 & 23 & 30 & 54 & 3 & 53 & 46 & 25 & 16 \\
\hline
\end{tabular}


studied in detail to set up criteria for the recognition of annuli. Annuli on the scales of lake trout are difficult to find as they are not always indicated by the same characteristics. It was necessary, therefore, to decide what determined an annulus.

The most frequent characteristic indicating the presenoe of an annulus was the gradual bunching together of the circuli followed by an abrupt increase in spacing. These bands often were quite distinot on some scales. However, this characteristic alone was not sufficient for locating all annuli. Some were characterized by crossing over of the oirculi where growth had resumed again. The location of others was indicated by incomplete oirculi that did not extend completely around the scale. An annulus usually was located by use of all three oriteria. These criteria, arrived at independently, are essentially the same as those listed by Cable (1956) for the recognttion of annuli on the scales of Lak Michigan lake trout.

Success in reading a scale hinged upon the proper interpretation of the area around the foous. Interpretation of the circuli in this area was the most difficult, but once solved, reading the rest of the scale was relatively easy. A check was located near the focus on all scales. This was defined as an annulus at first, but after applying the above criteria on a number of scales, it was rejected. Cable (1956) found this central check on the scales of both stocked and wild lake trout from Lake Michigan. She designated it as the 0-mark.

After the aging criteria were established, the soales were read independently two times. Where first and second readings disagreed, the soale was read again until an age was decided upon. Scales of the older fish were difficult to read, and the accuracy of the age assigned to these fish is doubtful. However, for purposes of comparison, all scales were assigned an age.

Comparison was then made between age determined by reading 
branchiostegal rays and age assigned by reading scales (figure 5). With those flsh where the assigned age by the two methods disagreed, both the rays and soales were again studied independently. Any errors found in previous readings were corrected. If no definite errors were located, the ages assigned were not changed. Almost all of the errors found were in scale readings.

In the first comparison 70.6 peroent of the soales agreed in age with the branohiostegal rays. After an independent re-reading of scales and rays, agreement was much closer (table 4). Table 5 shows the area of disagreement between the two readings. As can be seen, where the two readings disagreed, the fish were aged younger by scale readings than by ray readings. On scales of older fish it is difficult to locate all annul1.

From this oomparison. it would seem that the branohiostegal-ray method is at least as accurate as the soale method for determining age of lake trout. The branchiostogal rays have the added advantage of retaining a - lear pattern on older fish because the rays do not become worn and defaced with age as sorles do.

Age of maturity

To see if age assigned from the branchiostegal-ray readings agreed with the normal age when lake trout mature, the gonads of the lake trout from Fish Lake were examined to determine sex and stage of maturity. The classification used was that described by Lagler (1950). As the oollection was made during the summer, at a time when the lake trout were not spawing, the fish were classified as either mature or immature. If eggs were grossly visible or if the testes showed much development, the fish were olassified as mature.

As the fall spawing period approached, it was noticed that some of the young female fish classified as mature were not ready to spawn. Eggs were risible but not developed sufficiently for spawning in 1956. In this olassifioation, then, maturity as indicated by gonad development 

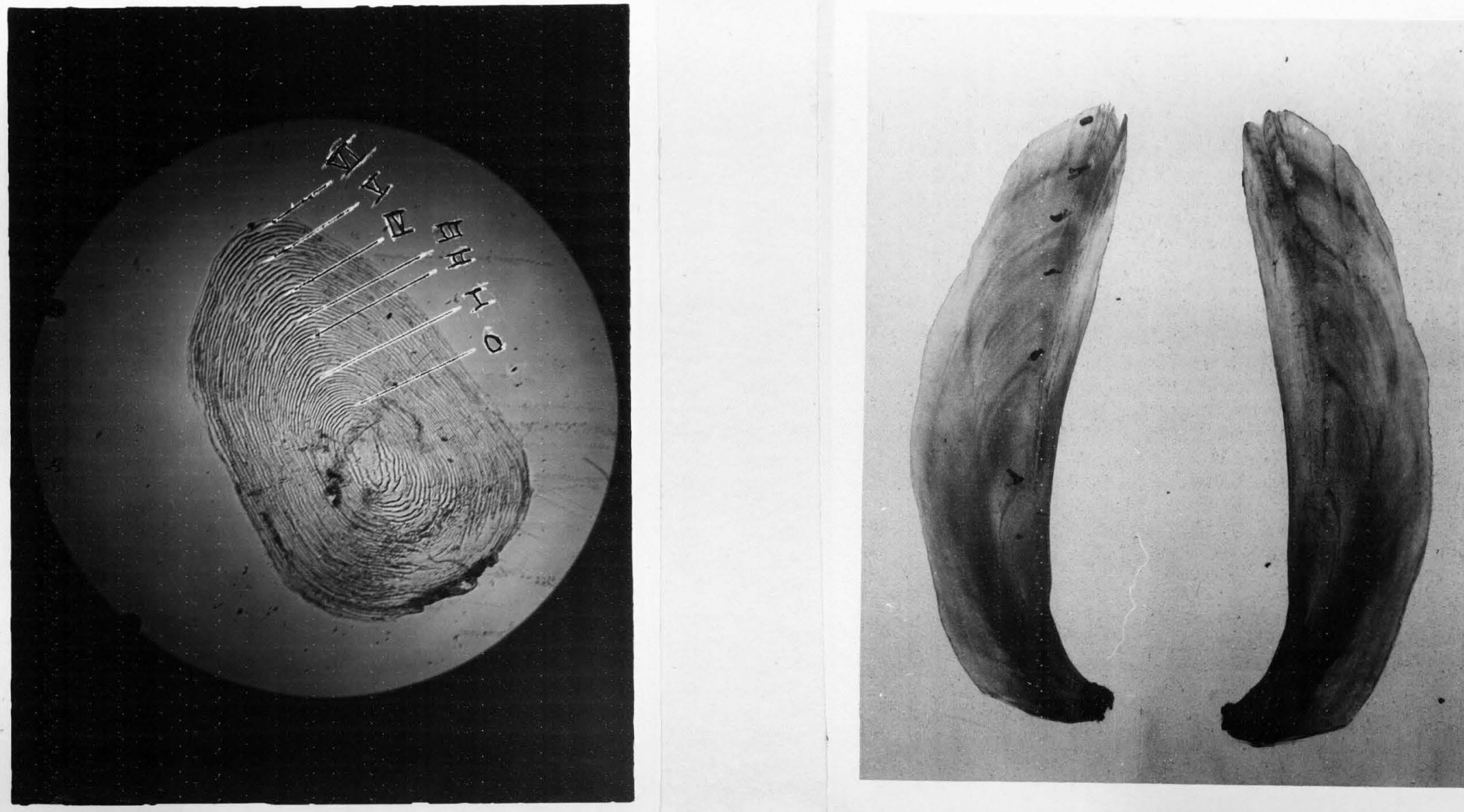

Plgure 5. Branchiostegal rays and scele from a Fiah Lake Iake trout whose age was estimated at 6 years (It should bo recognized that the untouched photographs of branchlogtegal rays cannot give the sane defree of Ieglbility attainable in practice by tilting the surface of the rays and altering the lighting.) 
Table 4. Agrapment in age of 305 Figh Lake lake trout by scale and branchiostegrlmray reading

\begin{tabular}{|c|c|c|c|c|c|c|c|c|c|c|c|c|c|c|c|c|}
\hline rags (years) & $I$ & 2 & 3 & 4 & 5 & 6 & $?$ & 8 & 9 & 10 & 11 & 12 & 13 & 14 & 15 & 16 \\
\hline Number of $\mathrm{figh}$ & 1 & 9 & 12 & 68 & 57 & 94 & 33 & 10 & 6 & 1 & 2 & 2 & 1 & 3 & 3 & \\
\hline $\begin{array}{l}\text { Percent agrement } \\
\text { of rays and scales }\end{array}$ & - & 90 & 92 & 98 & 98 & 97 & 97 & 90 & 100 & 100 & 66 & 66 & 33 & 66 & & \\
\hline
\end{tabular}


Table 5. Amount of disagreement in age between branchiostegal-ray method and soalo method of $8 \mathrm{~F}$ ish Lake lake trout 11 yoars of ago and older

$\begin{array}{lllllllll}\begin{array}{l}\text { Age aocording to } \\ \text { ray readings (yers) }\end{array} & 11 & 12 & 11 & 14 & 15 & 16 & 16 & 16 \\ \begin{array}{l}\text { Age according to } \\ \text { scale readings (years) }\end{array} & 8 & 11 & 13 & 15 & 13 & 15 & 15 & 15 \\ \text { Difference } & -3 & -1 & -1 & 1 & -2 & -1 & -1 & -1\end{array}$


may occur a year before spawning actually takes place. This would place the age of true maturity $\mathbf{2 8}$ indicated by spawning at one year later. Under the classification used, no fish under an assigned age of $4 \frac{1}{2}$ years had noticeable gonadal development. Forty-one percent of the $4 \frac{7}{2^{-}}$ year-old fish, 81 percent of the $5 \frac{1}{2}-y e a r-01 d$ fish, and 86 percent of the $6 \frac{1}{2}$-year-old fish were mature. All fish over an assigned age of $6 \frac{1}{2}$ years were mature.

This age of reaching maturity agrees favorably with other studies on lake trout. Surber (1933) raised lake trout to maturity in a fish hatchery. He secured his first eggs from females $4 \frac{1}{2}$ years old. These fish were 18 to 26 inches in length. Only a very few flish were mature at this early age. Royce (1943) found that very few male lake trout from Seneca Lake, New York, matured before their sixth year. Few females matured before their seventh year. Fry and Kennedy, as quoted by Royce, estimated the minimum age at maturity of lake trout of Lake Opeongo, Algonquin Park, Canade, as the fifth year of 1ife. According to the age determined by the branchiostegal rays, lake trout from Fish Lake would mature, therefore, at about the same average age as lake trout from many other waters. Direct evidenoe

The evidence presented thus far has been of an indirect nature, but in the final analysis, definite proof of any aging method must rely on the use of known-age fish. The assigned age must agree with the known age of the fish if the method is accurate.

Examination of several hundred fish with all age groups well represented would be ideal. However, mature lake trout of known age are very scarce in this country. Most of the fish which are available have been reared in hatcheries and are unsuitable, therefore, for aging studies because of unnatural growth conditions. Fortunately, branchiostegal rays from a small number of wild lake trout of known age were obtained from Lake Michigan. These fish, captured in 1949 and 1950, had been preserved 
in formalin originally and then transferred to alcohol. Hence, a certain amount of deterioration of the rays had taken place and the markings on the rays were not as olear as those found on branchiostegal rays of fresh fish. However, the characteristic ripples marking the annuli were plainly visible so that the rays could be aged with confidence. Figure 6 illustrates the branchiostegal ray from a lake trout whose known age was 4 years.

Branchiostegal rays from 37 Lake Michigan fish ranging from 3 to 5 years of age were examined without a knowledge of the age of any particular fish. Every effort wes made to make an unbiased reading of the rays. The number of annuli on 30 of the 37 rays agreed with the known age of the fish. The reason for this apparent disagreement in the age of 7 fish was found by checking the date of capture of these fish. All 7 were oaptured between February 4 and May 7, which is prior to the main growing season of lake trout. As Cable (1956) indicated, only 50 percent of Lake Michigan lake trout show new growth on the scales by June. This being true, it is not unusual to find fish captured before Nay without new growth visible on the rays. The final annulus of these 7 fish was assumed, therefore, to be on the edge of the ray, but that new growth was insufficient to mark its location. Under this assumption, all assigned ages agreed with the known age of the $37 \mathrm{fish}$, and hence, the fish were aged correctly by the branchiostegal ray method. 


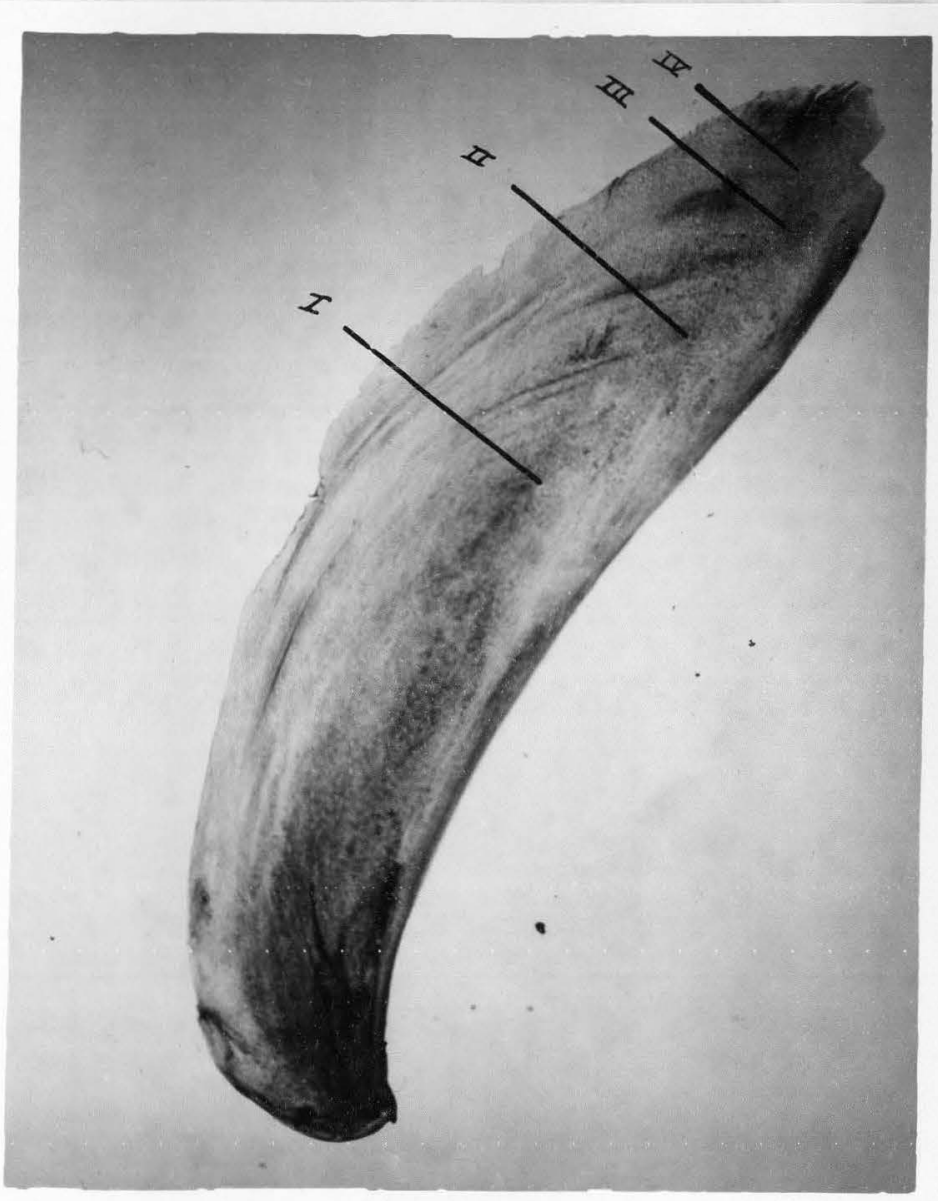

Figure 6. Branchiostegal ray from a Lake Michigan lake trout whose known age is 4 years 


\section{CONCLUSIONS}

From the above information, aging of lake trout by branchiostegal rays appears to be a reliable method for the particular populations studied. As the fish examined came from Fish Lake and Lake Michigan only, further study would have to be made to see if this method is valid for lake trout from other areas.

Using the oriteria given, the annuli can be located with little difficulty on most rays. The rays are easily cleaned and require no preservation or further preparation for reading. Age of the fish can be determined directly from the rays either without magnification or with a hand lens. For calculations of growth or more detalled study, the rays may be projected, but expensive mioroprojection equipment is unnecessary. A common 35-millimeter slide projector is suitable for all except the largest rays, and a lantern-side projector is satisfactory for rays of any size.

The branchiostegal rays of older fish are easier to read than the scales; this is a definite advantage. Further study should be made, however, with senile lake trout of known age when such fish are available. Further investigation is needed of the effects of spawning on the branchlostegal rays. The available information suggests that branohiostegal rays appear to be the answer to the question of deteriorating soales on older lake trout.

Age assigned to known-age fish agreed with their actual age, and all indirect evidence obtained from a population of unknown age agreed with the ages assigned. In comparison to the seales, the rays are relatively easy to read as the annuli are usually quite distinct. Thus the branohiostegal ray method of aging lake trout fulfills the requirements of a suitable aging method, and the possibilities of its general use should be investigated. 


\section{SUMMARY}

1. Branohiostegal rays of 342 lake trout were examined to determine their value as age and growth indicators. Three hundred and five fish of unknown age from Fish Lake, Utah, and 37 lake trout of known age from Lake Michigan were examined.

2. The annuli on the rays were defined as narrow transparent lines extending from the posterior end of the ray well into the lateral field. Annul1 were also marked by a wave or ripple in the struoture of the ray. 3. The relationship between body length and branchiostegal ray length was expressed by the formulas

$$
L=7.19 \not 4.45 \mathrm{R} \text {. }
$$

4. Indirect evidence supports the method. This included correlation between length of ray and body length, correlation between number of annuli and size of fish, comparison of scales and branchiostegal rays from the same fish, and comparison of calculated lengths and measured length. 5. Acoording to the age assigned from ray reading, Fish Lake lake trout mature between $4 \frac{1}{2}$ and $6 \frac{1}{2}$ years of age.

6. Direct evidence was obtained from 37 known-age fish, whose assigned age wh determined from the branchiostegal rays, agreed with the actual age of the Pish.

7. It is concluded that the branchiostegal-ray mothod is acourate and is relatively easy to use for the populations studied, and should be generally applioable. 


\section{LITERATURE CITED}

Appelget, John and Lloyd L. Smith Jr.

1951 The determination of age and rate of growth from vertebrae of the channel oatfish, Ictalurus lacustris punctatus. Trans. Am. Fish. Soc. 80:119-139.

Boyko, E. G.

1946 Age determination of fishes based on examination of fin-ray sections. Prog. Fish. Cult. 12(1):47-48.

Cablo, Louella $\mathrm{B}_{\text {. }}$

1956 Validity of age determination from scales, and growth of marked Lake Miohigan lake trout. U. S. Fish \& Wild. Ser. Bul. 107.

Cuerrier, J. P.

1951 The use of pectoral fin rays for determining age of sturgeons and other species of fish. Can. Fish. Cult. 11:10-17.

Hezzard, A. S.

1935 A preliminary study of an exceptionally productive trout water, Fishlake, Utah. Trans. An. Fish. Soo. 65:122-128.

Hile, Ralph

1950 A nomograph for the computation of the growth of fish from scale measurements. Trans. Am. Fish. Soc. 79:156-162.

Galtsoff, P. S.

1952 Staining of growth rings in the vertebrae of tuna (Thymnus thymnus). Copeia 2: 103-105.

Lagler, Karl $F$.

1950 Studies in freshwater fishery biology. Ann Arbor, Michigan: Edwards Bros. Inc. $231 \mathrm{pp}$.

LoCren, E. D.

1947 The determination of the age and growth of the perch Perce fluviatilis from the opercular bone. Jour. Animal Ecol. 16(2): $188-204$.

Lewis, William $\mathrm{K}$.

1949 The use of vertebrae as indicators of the age of the northern black bullhead Ameiurus m. melas (Rafinesque). Iowa State Coll. Jour. Sci. $23(2 \longdiv { 8 2 0 9 - 2 1 8 \div }$

MoConnell, William J.

1952 The opercular bone as an indicator of age and growth of the carp, Cyprinus carpio Linnaeus. Trans. Am. Fish. Soo. 818138149.

Menon, M. D.

1949 The use of bones, other than ot1liths in determining the age and growth rate of fishes. Jour. Du Conseil 16(1):311-340.

Royce, William. F.

1943 The reproduction and studies on the life history of the lake trout 


$$
\begin{aligned}
& \text { Cristivomer n. namaycush (Walbaum). Doctoral Dissertation } \\
& \text { Cornell University. }
\end{aligned}
$$

Surber, $T$.

1933 Rearing lake trout to maturity. Trans. Am. Fish. Soc. 63,64-68.

Van Oosten, John

1929 Life history of the lake herring (Leucichthys artedi LeSueur) of Lake Huron as revealed by its scales, with a oritique of the soale method. E. S. Bur. Fish. Bul. 44(Doc. 1053):265-428.

Zarbock, William $\mathrm{K}$.

Life history of the Utah sculpin, Cottus Bairdi semiscaber (Cope), in Logan River, Utah. Trans. Ame Fish. Soc. 81. 249259. 